\title{
Bibliotecas escolares do século XXI: implementando makerspaces
}

\author{
$21^{\text {st }}$ Century School Libraries: implementing makerspaces
}

\begin{abstract}
Jordan Paulesky Juliani
Doutor em Engenharia e Gestão do Conhecimento da Universidade Federal de Santa Caratina - UFSC, Brasil. Professor associado na Universidade do Estado de Santa Catarina. https://orcid.org/0000-0001-7823-6644

E-mail: jordan.juliani@udesc.br
\end{abstract}

Gabriela Vieira da Cunha Prates

Graduada em Biblioteconomia com Habilitação em Gestão da Informação pela Universidade do Estado de Santa Catarina - UDESC, Brasil. https://orcid.org/0000-0002-3635-4826

E-mail: gabivcprates@gmail.com

\section{Resumo}

Incorporando o Movimento Maker, a biblioteca escolar permite que os alunos passem por experiências de "colocar a mão na massa" e de aprendizado autônomo. Esta pesquisa objetivou definir os recursos necessários para a implementação de makerspaces em bibliotecas escolares. Para alcançar o objetivo proposto, discutiu-se a inovação no processo de ensino e aprendizagem e o uso de tecnologias; -se a origem, os conceitos e derivações dos makerspaces; mapearam-se as bibliotecas escolares que implementaram esses espaços ao redor do mundo; explicou-se o processo de planejamento e financiamento desses espaços, elencando os hardwares, materiais de consumo e materiais de makerspace utilizados nas escolas estudadas. Trata-se de uma pesquisa exploratória, bibliográfica com abordagem qualitativa. Concluiu-se que é preciso desenvolver e implementar a cultura maker na escola, antes mesmo de implementar o makerspace. Além disso, concluiu-se que os bibliotecários, incentivadores do acesso à informação, podem participar ativamente do seu desenvolvimento e implementação. Como uma das barreiras enfrentadas para a implantação dos makerspaces, pode-se considerar o financiamento uma das mais difíceis de serem superadas. Entretanto, não devem ser usadas como o motivo para não inovar.

Palavras-chave: Makerspace. Biblioteca escolar. Makerspaces em bibliotecas escolares. Educação. Tecnologia. Inovação.

\begin{abstract}
Incorporating the Maker Movement allows the students at school libraries to go through hands-on experiences, learning autonomously. This research aims to define the necessary resources for the implementation of makerspaces in school libraries. Innovation in teaching and learning processes and the use of technologies are discussed to achieve the proposed goal. The research also defines the origin, definitions, and derivations of makerspaces. It also maps the school libraries which implemented these spaces around the world. This makes it possible to explain the planning and financing process by listing the hardware, consumables, and makerspace materials used in the studied schools. This research is exploratory, bibliographic, and has a qualitative approach. It concludes that it is necessary to develop and implement the maker culture at school, even before the makerspace is implemented. It also shows that librarians, who encourage access to information, can actively participate in its development and implementation. Financing can be considered the most arduous barrier to overcome when implementing a makerspace. Even so, this should not be used as a reason for not innovating.
\end{abstract}

Keywords: Makerspace. School Library. School Library Makerspaces. Education. Technology. Innovation. 


\section{Introdução}

Para Lankes (2016), o potencial das bibliotecas nunca será concretizado se as suas fronteiras forem rígidas. Em seu livro, Expect More, o autor demonstra a importância das bibliotecas para a sociedade. Ele defendende a construção de uma nova Biblioteconomia, baseada no conhecimento e na comunidade, e não somente em livros e no acervo. Para esta construção, faz-se necessária a inovação.

Para promover inovações na biblioteca escolar, deve-se ter em mente a sua missão. A biblioteca escolar deve promover serviços que apoiem a aprendizagem, e dar acesso a livros e a obras que permitam o desenvolvimento do pensamento crítico e o uso efetivo da informação pela comunidade escolar (IFLA, 2000).

Para conseguir atingir a sua missão de transformar estudantes em cidadãos responsáveis, é necessário que o bibliotecário conheça seus usuários. Com seu público formado pelos chamados nativos digitais, fica cada vez mais necessário inovar e integrar as Tecnologias da Informação e Comunicação (TIC) ao ambiente da biblioteca.

Esta geração, nascida praticamente imersa na tecnologia, precisa de métodos de aprendizagem que consigam suprir suas necessidades informacionais (LEMOS, 2009). De acordo com Kenski (2003), novas metodologias de ensino precisam ser desenvolvidas de modo que motivem os nativos digitais a expressarem a sua opinião, promovendo a cooperação.

Conforme Ribeiro (2016), o uso de novas tecnologias, a partir do modelo pedagógico antigo, não trará novos resultados. Não é possível construir um novo fazer pedagógico utilizando velhas práticas, independente das novas ferramentas de apoio. As tecnologias são facilitadoras para essa conquista, que somente será obtida por meio de uma mudança do entendimento pedagógico, ou seja, de uma inovação.

A partir dessa reflexão, entende-se que os makerspaces se apresentam como uma forma de atrair novas gerações de alunos. Para Brown (2012 ${ }^{1}$ apud DALEY; CHILD, 2015, p. 43, tradução nossa), “o debate, o questionamento, a crítica e a necessidade humana de investigar e resolver problemas estão no cerne do aprendizado baseado em questionamentos e formam a base do Movimento Maker".

\footnotetext{
${ }^{1}$ BROWN, K. B. Seeking questions, not answers: the potential of Inquiry-Based Approaches to Teaching Library and Information Science. Journal of Education for Library and Information Science, Seattle, v. 53, n. 3, p. 189-199, 2012. Disponível em: https://www.jstor.org/stable/23249111. Acesso em: 10 ago. 2019.
} 
Incorporando o Movimento Maker, a biblioteca escolar procura fazer com que os alunos passem por experiências de "colocar a mão na massa", onde podem desenvolver projetos que envolvam a construção de artefatos físicos. Com isso, os alunos passam por experiências de construção do conhecimento de forma independente, através do processo ativo de descoberta (DALEY; CHILD, 2015).

De acordo com Houston (2013), os makerspaces são espaços comunitários que fornecem instalações, ferramentas e conhecimento para que os seus usuários criem novos produtos. Sendo assim, um espaço dedicado ao Movimento Maker na biblioteca escolar promoveria uma transformação do ambiente, tornando-o um lugar de investigação prática e aprendizagem participativa (HOUSTON, 2013).

Azevêdo (2019) defende que nenhuma ferramenta técnica ou tecnológica possibilita a igualdade ou diversidade. Por tanto, do ponto de vista pedagógico, o makerspace é extremamente relevante, já que de acordo com Lamb (2015), ele proporciona aos alunos um espaço para criar, construir e expressar ideias, por meio de produtos individuais e colaborativos. Jesus (2019) defende que as escolas são espaços em potencial para a implementação de um makerspace, já que eles estimulam a criatividade, habilidade que auxilia o processo educativo e pedagógico dos estudantes. Os makerspaces promovem a sociabilidade entre alunos de diferentes grupos sociais, que não teriam a oportunidade de trabalhar juntos e construir projetos fora deste espaço (KURTI, R.; KURTI, D.; FLEMING, 2014a).

Ao criar um makerspace, na biblioteca escolar, o bibliotecário institucionaliza esse movimento, desenvolvendo parcerias pedagógicas com a comunidade escolar. Com este espaço, aumentam-se as oportunidades de aprendizagem, habilidades e conhecimentos dos alunos, por meio da construção de uma comunidade dentro do ambiente escolar (DALEY; CHILD, 2015).

Mais comum no contexto de bibliotecas universitárias ou públicas, ou de contextos fora de ambientes de unidades de informação, os makerspaces em bibliotecas escolares são pouco abordados na literatura brasileira. Apesar de ser uma tendência fora do Brasil, esta temática ainda possui pouca representatividade no nosso país.

Não é um fato surpreendente, já que as bibliotecas escolares brasileiras, de modo geral, possuem pouco investimento e são pouco valorizadas. Mesmo que a Lei 12.244/10 (BRASIL, 
2010), tenha determinado a criação de bibliotecas em todas as escolas brasileiras, até o ano de 2020, esta realidade ainda está longe de ser alcançada (CANUTO, 2017).

Em relação à implementação de makerspaces no Brasil, de acordo com Gomes et al. (2017, p. 304, grifo nosso):

Poucas são as referências sobre como adotar atividades maker em escolas no Brasil e as dúvidas sobre o investimento, espaço, faixa etária atendida, riscos envolvidos, planejamento pedagógico, avaliação e relação com o currículo estão apenas começando a ser respondidas.

Assim sendo, a realidade da implementação de um makerspace em uma biblioteca escolar brasileira parece distante. Com as dificuldades já enfrentadas por estas bibliotecas, como encontrar apoio para desenvolver um espaço como esse? Quais os benefícios que este espaço pode trazer para a comunidade escolar? Como adaptar esta temática para a realidade brasileira? Realmente vale a pena investir em iniciativas como essa?

Guiada pela pergunta "Quais são os recursos necessários para implementar makerspaces em bibliotecas escolares?", esta pesquisa serviu como inspiração para a construção destes espaços, que já são tendência mundial no Brasil.

\section{O que é Makerspace?}

Daley e Child (2015) afirmam que hoje vivemos em uma sociedade onde as tecnologias são aperfeiçoadas a cada dia. Isso resulta em uma sociedade descartável, já que assim que saímos de uma loja, já estamos com um produto “desatualizado". Por isso, as autoras defendem que cada vez mais habilidades de engenharia e tinkering ${ }^{2}$ precisam ser desenvolvidas. É nisso que reside a ideia dos makerspaces: um local para inventar, compartilhar habilidades, questionar, consertar, reinventar, criar e pensar.

Para Santos Neto e Zaninelli (2017), o makerspace é um espaço para criar projetos individuais ou coletivos a partir de tecnologias e ferramentas que são disponibilizadas. Rivas (2014) descreve os makerspaces como espaços físicos operados pela comunidade, que disponibilizam ferramentas e equipamentos como impressoras 3-D, cortadores a laser, ferros

\footnotetext{
2 Não há uma palavra em português que passe o significado da palavra tinker no contexto utilizado nos makerspaces. Por isso, foi definido que esta palavra seria utilizada na sua forma original, do inglês, que representa alguém sem habilidades específicas que tenta reparar ou consertar coisas de forma experimental. Tinkering, palavra derivada de tinker vai ao encontro deste mesmo significado, mas refere-se ao ato de fazer uma pequena mudança em algo para tentar melhorar ou reparar.
} 
de solda, materias artísticos e artesanatos, onde as pessoas aprendem juntas e colaboram em projetos.

Santos Neto e Zaninelli (2017) veem a cultura maker como condição primordial para que os makerpaces atinjam seus objetivos. É preciso desenvolver e implementar a cultura maker, antes mesmo de implementar o makerspace. Desta forma, evita-se que o espaço se torne apenas mais um "laboratório" disponível, mas sem muita usabilidade. Despertar o interesse, dos futuros usuários, pelo novo e pelo aprendizado autônomo é essencial para que este espaço prospere.

\section{Cultura e Movimento Maker}

De acordo com Hatch (2014 3 apud GILBERT, 2017), a cultura maker é baseada no compartilhamento e colaboração. Ela foca na criação, ao invés do consumo, trazendo uma agenda para mudança social e pessoal. Bagley (2013) constata que a filosofia do empoderamento faz parte desta cultura, já que por meio da criatividade e da inovação os indivíduos internalizam e reconhecem a sua capacidade de pensar e agir. Sendo assim, os usuários saem do espaço conscientes de suas capacidades. A partir desta filosofia proveniente da cultura maker, surge então o movimento maker.

Este movimento surgiu pela esperança de uma educação progressista, propagada pelo Instituto de Tecnologia de Massachusetts (MIT) e pelos centros de tecnologias no Vale do Silício, nos Estados Unidos. Eles consideram que o Movimento Maker é ancorado na Teoria do Construtivismo de Piaget (MARTINEZ; STAGER, 20134 apud RIBEIRO, 2016).

De acordo com os autores, esta teoria defende que, apesar da aprendizagem ocorrer de forma interna no indivíduo, ela se fortalece a partir de atividades que façam com que ele realmente sinta a tarefa de aprender e a veja como algo compartilhável. Ela estabelece uma postura de como a aprendizagem ocorre, sem precisar estabelecer um currículo ou um conjunto de regras, de forma a garantir a autonomia do aprendiz. O Movimento Maker parte do pressuposto de desenvolver ações de criação, as quais incentivam o maker a controlar e a se

\footnotetext{
${ }^{3}$ HATCH, M. The maker movement manifesto: rules for innovation in the new world of crafters, hackers and tinkerers. New York: Mcgraw-hill, 2014.

${ }^{4}$ MARTINEZ, S. L.; STAGER, G. Invent to learn: making, tinkering, and engineering in the classroom. Kindle edition. Canada: Constructing Modern Knowledge Press, 2013.
} 
responsabilizar pela sua própria aprendizagem, transformando o aprendiz em protagonista do seu processo educacional.

Para Ribeiro (2016), este movimento contempla a abordagem de jardim de infância proposta por Resnick (2007). Esta abordagem engloba a criatividade, a inovação, o surgimento de novas ideias, o protagonismo e o empoderamento na construção do conhecimento. A autora defende que estas ações fortalecem o Pensamento Reflexivo, que promove o avanço da atividade cognitiva, potencializando a aprendizagem e despertando a inquietação e a curiosidade pelo conhecimento.

Gasque (2008) afirma que as atividades que proporcionam o Pensamento Reflexivo possuem um grande potencial para promover a educação transformadora. Essa abordagem resulta em uma educação emancipatória, autônoma, responsável e ética, já que ela considera as experiências tanto dos estudantes quanto dos educadores e da própria comunidade. Ribeiro (2016) constata que esta percepção é alinhada à pedagogia por projetos de Dewey (1979), que defende que a escola não seria a preparação para a vida, mas sim a própria vida.

\section{Makerspace Educacional e as Bibliotecas Escolares}

Conforme Kurti, R., Kurti, D. e Fleming (2014b), os makerspaces, fora do contexto educacional, não possuem a aprendizagem como seu objetivo primário, eles funcionam mais como um playground para adultos. Trazendo para o contexto educacional, essa visão de playground se mantém, porém é usada com o intuito de promover um aprendizado mais profundo através dos questionamentos aprofundados.

Para os autores, a premissa da educação maker é a autonomia do aluno. O foco é numa abordagem onde os alunos são guiados, através das ferramentas e tecnologias disponibilizadas estrategicamente pelos professores, para criar o seu próprio aprendizado por suas próprias razões. Essa atuação coadjuvante do professor permite que os alunos desenvolvam diversos questionamentos, curiosidade e um pensamento mais crítico, permitindo que os alunos descubram os conceitos que o professor pretende que eles aprendam.

Gershenfeld (2005 5 apud HOUSTON, 2013, p. 26) argumenta que muitos educadores acreditam nos benefícios trazidos por ambientes informais, como os makerspaces. Para o autor,

\footnotetext{
${ }^{5}$ GERSHENFELD, N. Fab: the coming revolution on your desktop: from personal computers to personal
} fabrication. New York: Basic Books, 2005. 
Bibliotecas escolares do século XXI: implementando makerspaces

a informalidade pode apoiar a aprendizagem em disciplinas de uma forma mais profunda e significativa em comparação às informações recebidas por meio de livros didáticos ou palestras formais.

Kurti, R., Kurti, D. e Fleming (2014b) ressaltam que os makerspaces educacionais podem revolucionar o ensino e a aprendizagem através de sua filosofia construcionista, onde os professores incentivam o aluno a questionar e produzir suas próprias respostas. Para os autores, um "makerspace educacional é mais um discurso motivacional sem palavras do que uma sala de aula" (KURTI; KURTI; FLEMING, 2014b, p. 11, tradução nossa).

Para Ribeiro (2016), o educador contemporâneo precisa ter a capacidade de atender a sociedade em rede, que hoje é afogada na sobrecarga de informações, por meio de habilidades de curadoria da informação. Sendo essa uma habilidade inerente ao bibliotecário, fica ainda mais claro que o desenvolvimento de makerspaces em bibliotecas escolares podem trazer grandes benefícios ao ensino. Kleon (2013, p. 145) afirma que "aqueles que estarão à frente serão aqueles que souberem o que deixar de fora, para assim poderem se concentrar no que realmente é importante".

Sendo assim, os bibliotecários escolares apoiam os professores e alunos na mudança para este novo modelo de aprendizagem, auxiliando no processo colaborativo de busca e entendimento da informação (TODD, $2006^{6}$ apud DALEY; CHILD, 2015, p. 43). De acordo com Kuhlthau (2010, p. 17, tradução nossa, grifo nosso),

Bibliotecas escolares são um componente essencial para as escolas da era da
informação. Os bibliotecários escolares são parceiros vitais na criação de escolas
que permitam aos alunos aprender através de vastos recursos e múltiplos canais de
comunicação. Os professores não podem fazer isso sozinhos. Os bibliotecários
escolares são agentes primários nas escolas dos alunos do século XXI. As bibliotecas
escolares são centros de aprendizagem dinâmicos em escolas da era da
informação.

Para a autora, a aprendizagem baseada na investigação desenvolve novas habilidades e competências que apoiam o ensino do uso de tecnologias de forma criativa. Para Lamb (2015, p. 56, tradução nossa), “[...] a biblioteca sempre foi um lugar para criar e compartilhar ideias”. Assim, os makerspaces surgiram como uma recente reinvenção do ambiente da biblioteca, que permite o desenvolvimento da criatividade. Criatividade esta que, de acordo com Ribeiro (2016), é uma característica que está sendo colocada de lado, pois o senso comum acredita que

\footnotetext{
${ }^{6}$ TODD, R. J. From learning to read to reading to learn: school libraries, literacy and guided inquiry. In: ANNUAL CONFERENCE OF INTERNATIONAL ASSOSSIATION OF SCHOOL LIBRARIANSHIP, 36., 2006, Lisboa. Anais [...]. Lisboa: IASL, 2006. p. 1-18.
} 
é herança genética, fazendo com que oportunidades de desenvolver ações criativas sejam perdidas.

Daley e Child (2015) defendem que as bibliotecas escolares são o ambiente natural dos makerspaces educacionais, já que possuem bibliotecários escolares especializados em encontrar informações, que podem auxiliar no processo de busca de seus usuários. A partir do momento em que uma biblioteca escolar incorpora o Movimento Maker, ela propicia um lugar onde os alunos podem fazer a tecnologia, ao invés de apenas usá-la. Desta forma, as bibliotecas escolares passam a ser vistas como algo a mais que um depóstito de livros. Elas passam a ser vistas como um local que vai além do aprendizado e que permite criar e inventar. Os alunos passam a se sentir pertencentes ao espaço da biblioteca e curadores do seu próprio conhecimento. Com isso, a biblioteca se transforma, tornando-se movimentada, e passa a ser considerada como o coração da escola (GRAVES, 2014).

\section{Procedimentos Metodológicos}

Esta pesquisa é classificada como uma pesquisa exploratória, bibliográfica e de abordagem qualitativa. Neste tipo de pesquisa, os dados são analisados de forma indutiva, apresentando a interpretação dos fenômenos e a atribuição de significados (PRODANOV; FREITAS, 2013).

Para alcançar os objetivos desta pesquisa, foi elaborado um questionário online, através da plataforma LimeSurvey, que ficou disponível para os respondentes durante o período de 14 dias (23/10/2018 a 05/11/2018). Ele possui um total de 51 perguntas, divididas em 9 módulos:
a) Seu perfil;
b) Planejamento;
c) Financiamento;
d) Pessoal e qualificação;
e) Espaço;
f) Hardware;
g) Materiais de consumo; 
h) Materiais de makerspace;

i) Módulo de agradecimento.

Seis diferentes fontes de informação ${ }^{7}$ foram utilizadas para relacionar os makerspaces educacionais ao redor do mundo, determinando, assim, o universo da pesquisa:

a) Google Groups sobre Makerspaces Educacionais;

b) Revisão de Literatura: foram selecionados os makerspaces de escolas citados nos artigos e textos da revisão de literatura desde trabalho;

c) NAIS (National Association of Independent Schools - Associação Nacional de Escolas Independentes): foram incluidas todas as escolas da lista;

d) Google Maps Personalizado - Makerspaces: foram selecionados todos os makerspaces de escolas;

e) Makerdirectory: foi pesquisada a palavra-chave "school" e selecionados os makerspaces;

f) CTE Makeover Challenge (Desafio da Reforma CTE): foram selecionadas as escolas ganhadoras do desafio.

Nesse levantamento, foram encontrados 211 makerspaces em escolas, sendo 51 localizados dentro da biblioteca escolar (ver Figura 1).

Figura 1 - QR Code: Levantamento

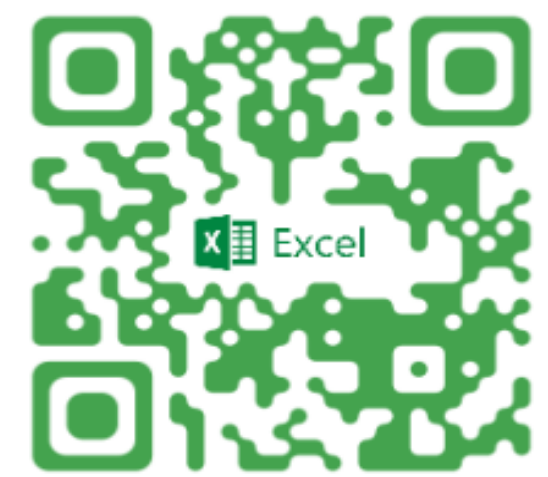

Fonte: elaborado pelos autores (2020)

O mapa abaixo ilustra a localização dos makerspaces listados, sendo os makerspaces que se encontram em bibliotecas escolares marcados em roxo (ver

\footnotetext{
${ }^{7}$ Hiperlink disponível. Clique nas fontes para abrí-las.
} 
Figura 2).

Figura 2 - Mapa dos makerspaces

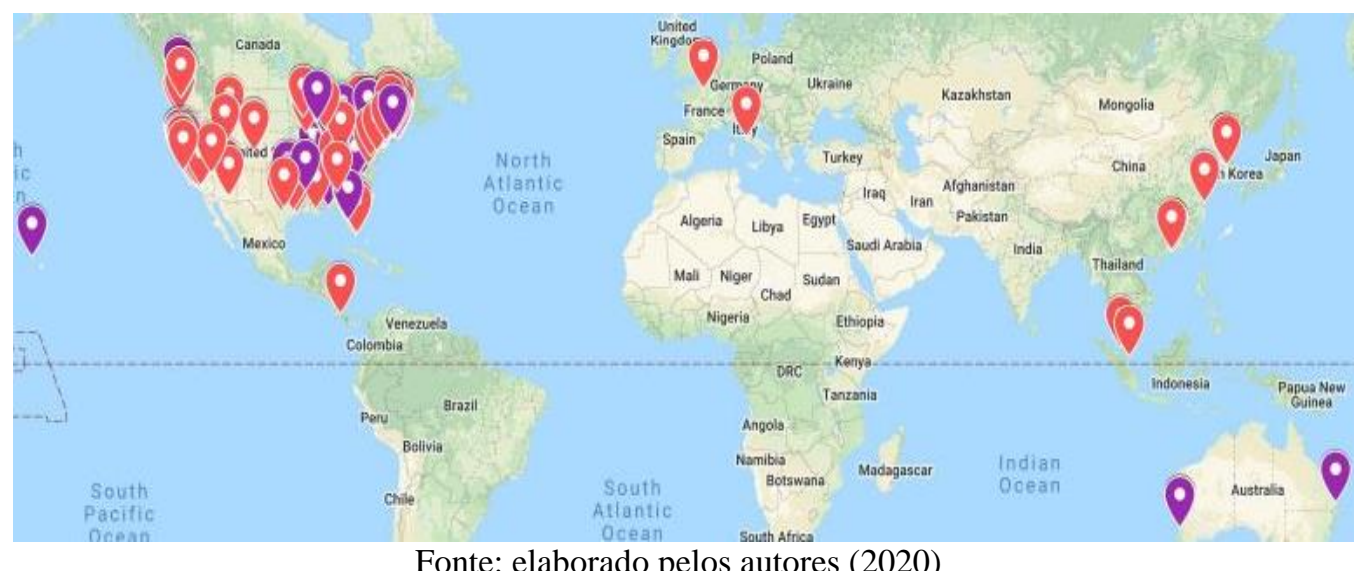

Fonte: elaborado pelos autores (2020)

Para ter acesso ao mapa com todas as informações, acesse o Qr Code da Figura 3.

Figura 3 - QR Code: Mapa Makerspaces Educacionais

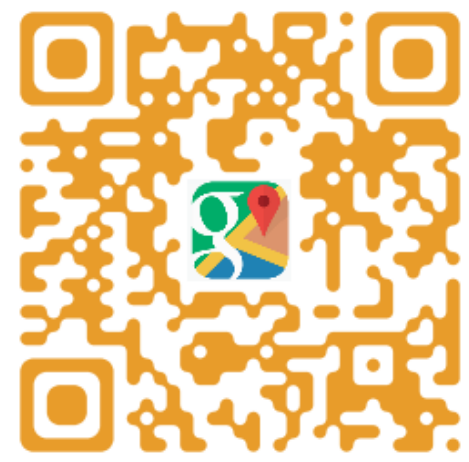

Fonte: elaborado pelos autores (2021).

Os dados coletados nessa pesquisa, por meio de questionário e de entrevista, podem ser acessados pelo Qr code da Figura 4.

Figura 4-QR Code: dados coletados nessa pesquisa por meio de questionário e de entrevista

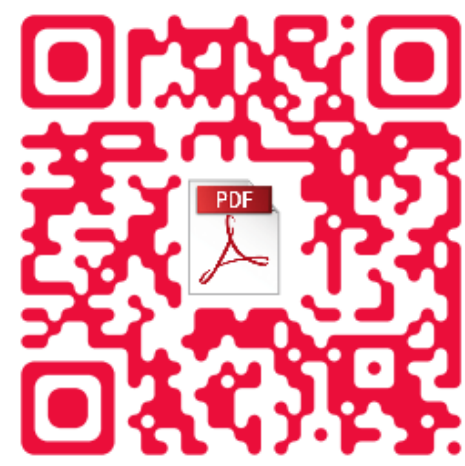

Fonte: elaborado pelos autores (2021).

Bibl. Esc. em R., Ribeirão Preto, v. 7, n. 2, p. 42-60, 2021. 


\section{Discussão dos Resultados}

O questionário foi aplicado de forma online com bibliotecários escolares que implementaram makerspaces. Esses bibliotecários foram contatados a partir da lista de e-mails proveniente do levantamento dos makerspaces educacionais (Figura 1). Obteve-se o retorno de 7 profissionais que responderam à pesquisa por completo, chamados de respondentes.

$\mathrm{Na}$ análise das respostas, identificou-se que todos os respondentes são bibliotecários escolares. É importante observar que, por mais que o questionário tenha sido enviado para diversos bibliotecários ao redor do mundo, todos os respondentes são dos Estados Unidos.

Grande parte dos bibliotecários entrevistados responsáveis pela implementação do makerspace trabalham sozinhos. Fica claro, portanto, que as premissas "seria impossível implementar um projeto como este sem uma equipe" e "não posso criar um makerspace na minha biblioteca pois não tenho tempo" foram rebatidas nessa pesquisa.

Em relação às tecnologias, todos os bibliotecários afirmaram ser possível abrir um makerspace sem equipamentos caros. O custo das tecnologias, portanto, não pode ser considerado uma barreira para inovar. Até porque, ao fazer um orçamento dos equipamentos citados, percebe-se que estes atualmente tornaram-se mais acessíveis (ver

Tabela 1).

Tabela 1 - Custo de equipamentos tecnológicos no Brasil

\begin{tabular}{|c|c|}
\hline Tecnologia & Preço \\
\hline Impressora 3D (Flashforge Finder) & $\mathrm{R} \$ 2.600,00$ \\
\hline Arduino Maker (1 Kit) & $\mathrm{R} \$ 260,00$ \\
\hline Cortador de Vinil & $\mathrm{R} \$ 2.450,00$ \\
\hline Máquina de Costura Portátil & $\mathrm{R} \$ 350,00$ \\
\hline Impressora de Fotos & $\mathrm{R} \$ 815,00$ \\
\hline Realidade Virtual: Google Cardborard (Kit com 20) & $\mathrm{R} \$ 400,00$ \\
\hline Mini Cortador a Laser $(\mathrm{CNC})$ & $\mathrm{R} \$ 3.300,00$ \\
\hline TOTAL & $\mathrm{R} \$ 10.175,00$ \\
\hline
\end{tabular}

Fonte: elaborado pelos autores (2021). 
Ao observar a tabela, podemos perceber que, com aproximadamente 11 mil reais, já é possível adquirir todas as tecnologias citadas como principais pelos respondentes. Esse valor pode ser arrecadado através de doações, parcerias, ou por meio de croudsourcing.

O custo da implementação foi calculado por meio da média dos gastos totais que os respondentes tiveram ao implementar seus makerspaces, com cada uma das seguintes categorias:
a) Pessoal;
b) Reformas;
c) Equipamentos Tecnológicos;
d) Suprimentos;
e) Softwares;
f) Mobiliário.

Uma grande barreira a ser considerada é a questão do espaço. As bibliotecas brasileiras, em sua maioria, possuem pouco espaço. Para driblar esta barreria, recomenda-se investir em mobílias compactas e portáteis, que podem ser usadas tanto por usuários do makerspace quanto pelos da própria biblioteca.

Nos Estados Unidos, encontra-se facilmente mobiliários como esse. A 
Bibliotecas escolares do século XXI: implementando makerspaces

Figura mostra algumas destas mobílias e seus respectivos preços em reais. Deve-se considerar mais valores em relação a taxas de importação, ou até mesmo avaliar a possibilidade de produzir móveis sob medida inspirados nestes modelos. 
Figura 5 - Mobiliário de makerspaces
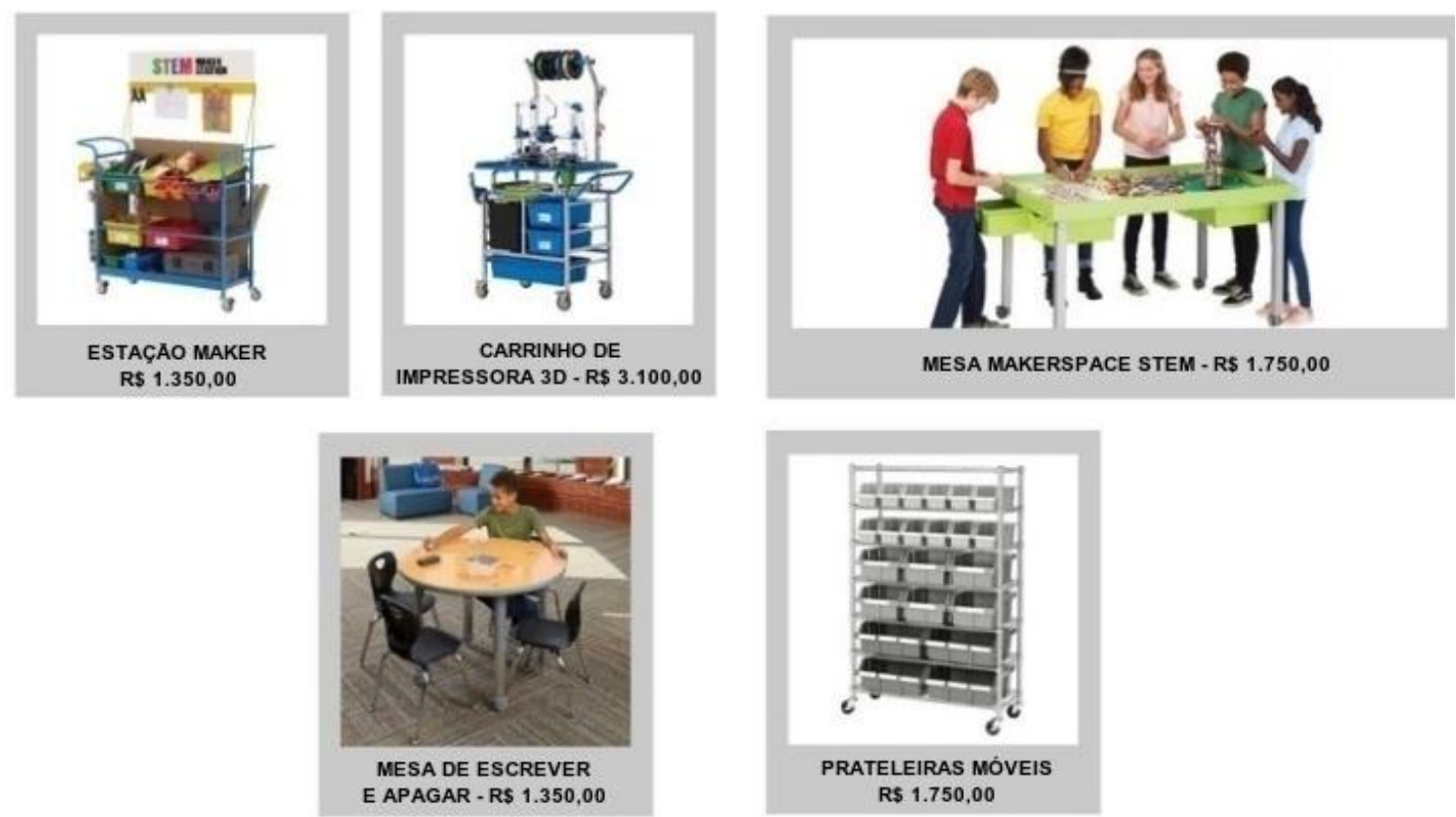

Fonte: elaborado pelos autores, com fotos do Google Imagens (2021).

Os materiais de consumo e de makerspace podem ser facilmente encontrados à venda no Brasil. Estimou-se que, para a implementação do makerspace, seria necessário o investimento de aproximadamente 8 mil reais para os materiais de consumo e 16 mil reais para os mateirias de makerspace (ver Figura ). Essa estimativa considera o valor de todos os materiais de consumo e de makerpaces citados pelos respondentes.

Figura 6 - Materiais de makerspaces

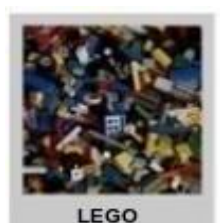

LEGO

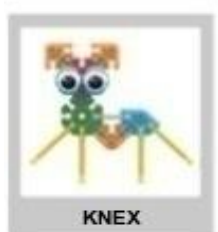

KNEX

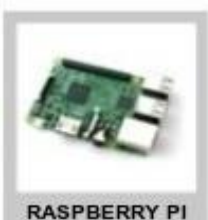

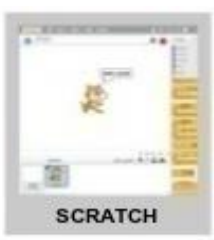

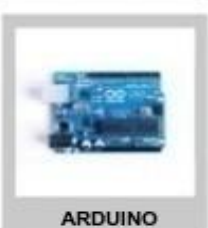

ARDUINO

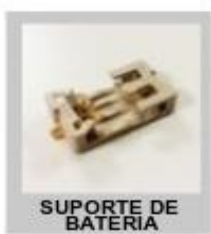

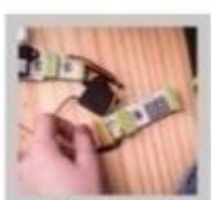
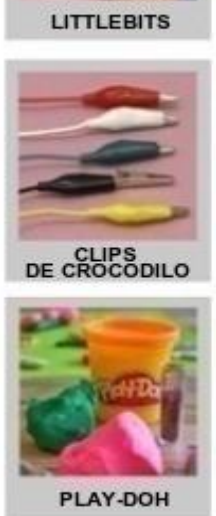
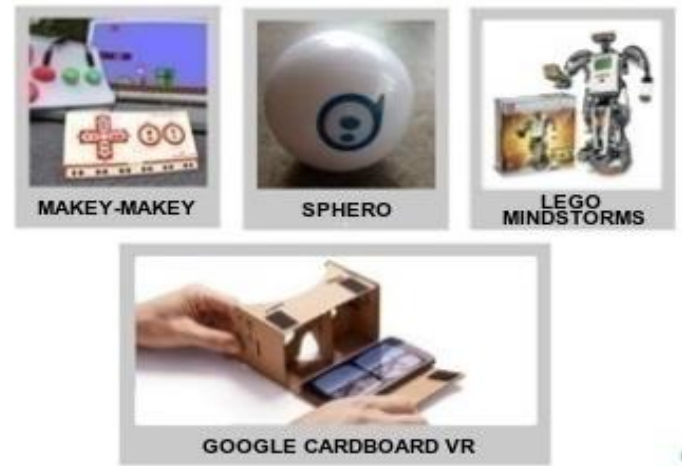

GOOGLE CARDBOARD VR

Fonte: elaborado pelos autores, com fotos do Google Imagens (2021).

Concluindo, os gastos para a implementação de um makerspace, incluindo materiais de consumo, de makerspace, mobiliário e equipamentos tecnológicos totaliza aproximadamente 
45 mil reais. É importante destacar que esse é o valor total considerando a compra de todos os materiais recomendados, inclusive dos aparelhos tecnológicos. Pode-se começar com um orçamento muito mais modesto, analisando quais itens deve-se dar preferência para aquisição, de acordo com a demanda informacional dos usuários de cada escola/biblioteca.

Resumindo, os recursos necessários para a implementação de um makerspace em uma biblioteca escolar são:

a) recursos em relação ao espaço: mobiliário compacto e portátil;

b) recursos materiais: materiais de consumo e materiais de makerspaces;

c) recursos tecnológicos: hardware;

d) recursos humanos: não há necessidade de aumentar esses recursos para além do que a biblioteca já é contemplada atualmente. Em relação ao tempo de dedicação do profissional ao espaço, de acordo com os respondentes, não há necessidade de investir mais de 15 horas semanais;

e) recursos financeiros: aproximadamente 45 mil reais para alcançar o makerspace já em sua forma plena.

Percebeu-se que em todas as escolas que participaram do questionário, a administração esteve sempre presente, apoiando desde o início. Na realidade brasileira, muitas vezes esse cenário não será encontrado. Será necessário convencer a administração sobre as vantagens da implementação de um espaço como esse. Para isso, é necessária a apresentação de um projeto formal, burocrático e muito bem estruturado. Com isso, provavelmente o tempo de elaboração do projeto até a sua implementação levaria mais do que os 6 meses levados pela maioria dos respondentes da pesquisa.

No que diz respeito às formas de financiamento possíveis, aqui no Brasil, temos diversas oportunidades como as vaquinhas online, pedidos de doações da comunidade escolar e do entorno etc.

\section{Considerações finais}

Esta pesquisa pretendeu contribuir para a área das bibliotecas escolares brasileiras, encorajando bibliotecários a investirem e a se dedicarem a projetos inovadores. Propagado pelo 
MIT e pelos centros de tecnologia no Vale do Silício, o Movimento Maker é uma tendência que facilita a adoção da tecnologia nas escolas. Ele contribui para o desenvolvimento de abordagens pedagógicas que incentivam o aprendizado autêntico, a inovação, a colaboração e o pensamento crítico, consideradas importantes habilidades para os alunos do século XXI.

É preciso desenvolver e implementar a cultura maker na escola, antes mesmo de implementar o makerspace. Deve se despertar o interesse pelo novo e pelo aprendizado autônomo dos alunos, mostrando que o incentivo para que o aluno construa o seu próprio conhecimento não faz com que os professores percam o seu espaço. Pelo contrário, faz com que eles atinjam a sua missão maior, de formar cidadãos preparados para o mundo.

Os bibliotecários, incentivadores do acesso à informação, podem apresentar essa cultura nas escolas e participar ativamente do seu desenvolvimento e da implementação dos makerspaces, acompanhando a evolução da educação. Os makerspaces podem ser utilizados para redesenhar o ambiente, estimulando os alunos a utilizar o espaço e agregando valor à biblioteca, fazendo com que ela deixe de ser vista como um depósito de livros e passe a ser vista como colaboradora ativa da educação. No entanto, apenas trazê-los para este ambiente não é suficiente.

É preciso desenvolver atividades maker que englobem os materiais da biblioteca. Para isso, é necessário que o bibliotecário possua uma participação ativa no desenvolvimento e no planejamento dessas atividades. Dessa forma, os alunos, professores e toda a comunidade escolar poderão perceber o valor e a importância da biblioteca, indo muito além da disponibilização do acervo.

O makerspace pode transformar a comunidade escolar, já que é um ambiente que promove o empoderamento, confiança, inclusão, sustentabilidade e o aprendizado autêntico. Esse espaço torna possível a interdisciplinaridade entre quaisquer disciplinas do currículo. Basta apenas o envolvimento dos professores de diferentes disciplinas em conjunto com o bibliotecário para a elaboração dos mais diversos tipos de atividades.

Ao analisar as barreiras enfrentadas pelos makerspaces, podemos considerar o financiamento como uma das mais complicadas para superar, já que a sua resolução vai além dos esforços do bibliotecário. Mesmo assim, esse problema pode ser resolvido aos poucos, principalmente depois do espaço estar funcionando e gerando resultados. 
Barreiras financeiras não devem ser usadas como o motivo para não inovar. Afinal, a inovação é uma habilidade essencial para o bibliotecário no século XXI, e a criatividade para trabalhar com pouco orçamento ou buscar financiamento em fontes externas faz parte dessa habilidade. Os makerspaces educacionais preparam os alunos para viver no mundo do futuro.

Recomendam-se novas pesquisas na área, já que, como mostrado anteriormente, a literatura brasileira sobre a temática de makerspaces em bibliotecas escolares ainda é muito escassa. Sugere-se que sejam feitas adequações no questionário da pesquisa para nova aplicação, com mais respondentes, para que se possa obter respostas com validação estatística.

Sugere-se, também, o desenvolvimento de pesquisas que se aprofundem nas questões de custos e de orçamentos para a realidade brasileira. Outra sugestão é uma pesquisa que apresente um manual de implementação de makerspaces em bibliotecas escolares brasileiras como produto. 


\section{Referências}

AZEVÊDO, L. S. Cultura maker: uma nova possibilidade no processo de ensino e aprendizagem. 2019. Dissertação (Mestrado em Inovação em Tecnologias Educacionais, Instituto Metrópole Digital) - Universidade Federal do Rio Grande do Norte, Natal, 2019. Disponível em: https://repositorio.ufrn.br/jspui/bitstream/123456789/28456/1/Culturamakernova_Azevedo_2 019.pdf. Acesso em: 19 jan. 2021.

BAGLEY, C. A. What is a makerspace?: ceativity in the library. American Library Association, 2013. Disponível em: http://www.ala.org/tools/article/ala-techsource/whatmakerspace-creativity-library. Acesso em: 20 dez. 2020.

BRASIL. Lei $\mathbf{n}^{0}$ 12.244, de 24 de maio de 2010. Dispõe sobre a universalização das bibliotecas nas instituições de ensino do País. Brasília: Casa Civil, 2010. Disponível em: http://www.planalto.gov.br/ccivil_03/_ato2007-2010/2010/lei/112244.htm. Acesso em: 18 mar. 2018.

CANUTO, L. C. Meta de universalizar bibliotecas nas escolas está longe de ser alcançada, dizem especialistas. Câmara dos Deputados, 2017. Disponível em:

http://www2.camara.leg.br/camaranoticias/noticias/EDUCACAO-E-CULTURA/547092META-DE-UNIVERSALIZAR-BIBLIOTECAS-NAS-ESCOLAS-ESTA-LONGE-DE-SERALCANCADA,-DIZEM-ESPECIALISTAS.html. Acesso em: 18 mar. 2018.

DALEY, M.; CHILD, J. Makerspaces in the school library environment. Access (10300155), Zillmere, v. 29, n. 1, p.42-49, 2015. Disponível em: http://search-ebscohostcom.ez74.periodicos.capes.gov.br/login.aspx? direct=true\&db=lih\&AN=101895199\&lang=ptbr\&site=ehost-live. Acesso em: 18 mar. 2018.

DEWEY, J. Como pensamos: como se relaciona o pensamento reflexivo com o processo educativo - uma reexposição. 4. ed. São Paulo: Ed. Nacional, 1979.

GASQUE, K. C. G. D. O pensamento reflexivo na busca e no uso da informação na comunicação científica. 2008. Tese (Doutorado em Ciência da Informação) - Faculdade de Economia, Administração, Contabilidade e Ciência da Informação, Universidade de Brasília, Brasília, 2008. Disponível em:

https://repositorio.unb.br/bitstream/10482/1344/1/TESE_2008_KelleyCristineGDiasGasque.p df. Acesso em: 10 jan. 2021.

GILBERT, J. Educational makerspaces: disruptive, educative or neither?. New Zealand Journal of Teachers' Work, Auckland, v. 14, n. 2, p. 80-98, 2017. Disponível em: http://hdl.handle.net/10292/11072. Acesso em: 18 mar. 2019.

GOMES, E. B. et al. A experiência de implantação de uma disciplina maker em uma escola de educação básica. In: CONGRESSO BRASILEIRO DE INFORMÁTICA NA EDUCAÇÃO, 6., 2017, Recife. Anais [...]. Recife: SBC, 2017. p. 303-312. Disponível em: http://www.br-ie.org/pub/index.php/wie/article/view/7248/5046. Acesso em: 18 mar. 2018.

GRAVES, C. Teen experts guide makerspace: make over. Knowledge Quest, Chicago, v. 42, n. 4, p. 8-13, 2014. Disponível em: http://link- 
galegroup.ez74.periodicos.capes.gov.br/apps/doc/A377575170/AONE?u=capes\&sid $=$ AONE\&xid=dca377f3. Acesso em: 18 mar. 2018.

HOUSTON, C. Makerspaces@your school library: consider the possibilities! Kentucky Libraries, Prospect, v. 77, n. 3, p. 26-28, 2013. Disponível em: http://search-ebscohostcom.ez74.periodicos.capes.gov.br/login.aspx?direct=true \&db=lih\&AN=89637184\&lang=ptbr\&site=ehost-live. Acesso em: 18 mar. 2018.

IFLA. Manifesto IFLA/UNESCO para biblioteca escolar. Tradução Neusa Dias Macedo. São Paulo: IFLA, 2000.

JESUS, D. L. Makerspace em bibliotecas escolares: uma análise bibliométrica. 2019. Dissertação (Mestrado em Gestão da Informação e Bibliotecas Escolares) - Universidade Aberta, 2019. Disponível em:

https://repositorioaberto.uab.pt/bitstream/10400.2/8560/1/TMGIBE_DeiseJesus.pdf. Acesso em: 19 jan. 2021.

KENSKI, V. M. Aprendizagem mediada pela tecnologia. Revista Diálogo Educacional, Curitiba, v. 4, n. 10, p. 1-10, 2003. Disponível em:

http://www2.pucpr.br/reol/pb/index.php/dialogo?dd1=786\&dd99=view\&dd98 $=$. Acesso em: 8 abr. 2020.

KLEON, A. Roube como um artista: 10 dicas sobre criatividade. Tradução de Leonardo Villa-Forte. Rio de Janeiro: Rocco, 2013.

KUHLTHAU, C. C. Guided inquiry: school libraries in the 21st century. School Libraries Worldwide, Tallahassee, v. 16, n. 1, p. 17-28, 2010. Disponível em: http://wp.comminfo.rutgers.edu/ckuhlthau/wp- content/uploads/sites/185/2016/02/GI-SchoolLibrarians-in-the-21-Century.pdf. Acesso em: 20 abr. 2018.

KURTI, R. S.; KURTI, D. L.; FLEMING, L. Practical implementation of an educational makerspace: part 3 of making an educational makerspace. Teacher Librarian, Bowie, v. 42, n. 2, p. 20-24, 2014a. Disponível em: http://link-

galegroup.ez74.periodicos.capes.gov.br/apps/doc/A397004755/AONE?u=capes\&sid=AONE

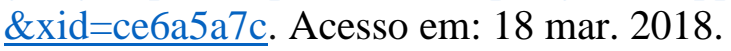

KURTI, R. S.; KURTI, D. L.; FLEMING, L. The philosophy of educational makerspaces: part 1 of making an educational makerspace. Teacher Librarian, Bowie, v. 41, n. 5, p. 8-11, 2014b. Disponível em: http://link-

galegroup.ez74.periodicos.capes.gov.br/apps/doc/A373680322/AONE?u=capes\&sid $=\mathrm{AONE} \& \mathrm{xid}=\mathrm{c} 45 \mathrm{e} 2 \mathrm{ef} 9$. Acesso em: 18 mar. 2018.

LAMB, A. Makerspaces and the School Library Part 1: where creativity blooms. Teacher Librarian, Bowie, v. 43, n. 2, p. 56-59, 2015. Disponível em: http://linkgalegroup.ez74.periodicos.capes.gov.br/apps/doc/A439185904/AONE?u=capes\&sid=AONE \&xid=d193225b. Acesso em: 18 mar. 2018.

LANKES, D. Expect more: melhores bibliotecas para um mundo complexo. São Paulo: FEBAB, 2016.

LEMOS, S. Nativos digitais x Aprendizagens: um desafio para a escola. Boletim Técnico do Senac: Revista da Educação Profissional, Rio de Janeiro, v. 35, n. 3, p. 39-47, 2009. 
Jordan Paulesky Juliani e Gabriela Vieira da Cunha Prates

Disponível em: http://www.bts.senac.br/index.php/bts/article/view/236/219. Acesso em: 15 jan. 2020.

PRODANOV, C. C.; FREITAS, E. C. Metodologia do trabalho científico: métodos e técnicas da pesquisa e do trabalho acadêmico. 2. ed. Novo Hamburgo: Feevale, 2013. Disponível em: http://www.feevale.br/Comum/midias/8807f05a-14d0-4d5b-b1ad1538f3aef538/E-book Metodologia do Trabalho Cientifico.pdf. Acesso em: 12 maio 2018.

RESNICK, M. All I really need to know (about creative thinking) I learned (by studying how children learn) in Kindergarten. In: ACM SIGCHI Conference on Creativity and Cognition, 6. 2007, Washington, DC. Proceedings [...]. Washington, DC: ACM, 2007. Disponível em: http://web.media.mit.edu/ mres/papers/kindergarten-learning-approach.pdf. Acesso em: 20 mai. 2020.

RIBEIRO, L. A. M. CuriouserLab: uma experiência de letramento informacional e midiático na educação. 2016. Tese (Doutorado em Ciência da Informação) - Faculdade de Ciência da Informação, Universidade de Brasília, Brasília, 2016. Disponível em: http://repositorio.unb.br/handle/10482/21279. Acesso em: 18 mar. 2018.

RIVAS, L. Creating a classroom makerspace. Educational Horizons, Melbourne, v. 93, n. 1, p. 25-26, 2014. Disponível em:

http://journals.sagepub.com/doi/abs/10.1177/0013175X14551701. Acesso em: 18 mar. 2018.

SANTOS NETO, J. A.; ZANINELLI, T. B. Biblioteca escolar com makerspace: um estudo de caso na Biblioteca Abraham Lincoln. Revista Brasileira de Biblioteconomia e

Documentação, São Paulo, v. 13, p. 2633-2656, 2017. Disponível em:

https://rbbd.febab.org.br/rbbd/article/view/1005. Acesso em: mar. 2020.

Artigo submetido em: 27 jan. 2021.

Artigo aceito em: 05 maio 2021. 